\title{
Value Based Purchasing and Nursing Case Management
}

\author{
Louise Pernisi ${ }^{1}$, Ronald Lagoe ${ }^{2 *}$, Barbara Drapola ${ }^{3}$, Shelly Littau ${ }^{2}$ \\ ${ }^{1}$ Upstate University Hospital-SUNY UMU, Syracuse, NY, USA \\ ${ }^{2}$ Hospital Executive Council, Syracuse, NY, USA \\ ${ }^{3}$ Crouse Hospital, Syracuse, NY, USA \\ Email: ^Hospexcl@cnymail.com
}

How to cite this paper: Pernisi, L., Lagoe, R., Drapola, B. and Littau, S. (2017) Value Based Purchasing and Nursing Case Management. Open Journal of Nursing, 7, 307317.

https://doi.org/10.4236/ojn.2017.72025

Received: January 7, 2017

Accepted: February 25, 2017

Published: February 28, 2017

Copyright ( $\odot 2017$ by authors and Scientific Research Publishing Inc. This work is licensed under the Creative Commons Attribution International License (CC BY 4.0).

http://creativecommons.org/licenses/by/4.0/ (c) (i) Open Access

\begin{abstract}
The implementation of value based purchasing will bring major changes to the delivery of health care in the United States. This effort is being led by the Medicare Access and CHIP Reauthorization Act (MACRA). Medicaid and private insurance plans are developing similar programs. These programs reflect a change in pay or incentives in the direction of primary and ambulatory care at the community level. This study described the use of nursing case management as a tool for monitoring and coordinating the impact of value based programs at the community level. It suggested that, under these programs, nursing case management can contribute to reduction of hospital admissions/discharges, emergency department visits, and hospital readmissions. This can be accomplished through monitoring of utilization levels for these indicators. These are major objectives of MACRA and related programs. The study also suggested that nursing case management can contribute to the development of new programs, such as Complex Care, as a means of reaching these objectives. The study included estimates of the costs and benefits of using case management to reduce hospital admissions for low severity of illness patients at the community level. It suggested that the service can provide important opportunities for health planning and development in this area.
\end{abstract}

\section{Keywords}

Hospital Utilization, Hospital Admissions, Hospital Emergency Departments, Managed Care, Nursing Case Management

\section{Introduction}

Important changes in the health care system of the United States are developing. As the national debate concerning the future of the Affordable Health Care Act 
continues, these changes will probably have a greater impact on the delivery and coordination of care [1].

A number of these developments comprise the value based purchasing programs focusing on improving the efficiency and outcomes of services through primary and ambulatory care. These include the Medicare Access and CHIP Reauthorization Act (MACRA) program that will take effect on January 1, 2017. They also include State Medicaid and private insurance value based purchasing programs [2] [3] [4] [5].

Unlike many previous initiatives, these programs focus on improving the outcomes and efficiency of care through primary and ambulatory care, rather than through hospitals. The MACRA program ties physician payments under the Medicare fee schedule to performance. It provides for 4 percent negative payment adjustments under the Medicare fee schedule for physicians who do not participate. Physicians who participate may obtain positive payment adjustments depending on the cost reductions that they generate [6] [7] [8].

Under MACRA, positive payment adjustments will depend on the extent to which each participating physician reaches quality and performance levels. These involve reducing hospital admissions, hospital readmissions, and emergency department visits. The program will substantially increase the focus on keeping patients out of the hospital. This means that physicians will be rewarded for judicious referrals across the health care continuum. The program has established the criteria and left it for providers to make the necessary adjustments.

The MACRA program also includes incentives for hospitals to reduce acute care costs. This will impact cooperative activities between physicians and hospital partners [6].

These developments are also consistent with the results of the general elections of 2016. The MACRA program was sponsored by Republicans when it passed both houses of Congress. It is also anticipated that Medicaid reform programs will address conservative concerns with the high costs of this payer [8] [9] [10].

In addition to MACRA, the Medicare Accountable Care Organization programs are an important component of the transition to alternative models for more efficient care. For each Accountable Care Organization, the program focuses on limiting the average level of Medicare spending during a three-year period. Accountable Care also addresses value based purchasing objectives. [11].

These programs have generated new interest in the use of nursing case management in health care as a means for adjusting utilization of services such as hospital admissions and emergency department visits. Historically, nursing case management has been used as a mechanism for coordination of health care services, especially for hospital functions such as discharge planning. Case management has also been employed in the monitoring of patients and coordination of services for disease management. Since the early 1980s, interest in case management as an interprofessional care delivery model has increased [12] [13]. Nursing case management is now performed in every health care setting pro- 
viding value to patients and their health care systems [14].

Under the Affordable Health Care Act, the use of registered nurses for care coordination increased because of the complexity of cases. This included a major emphasis on evidence based practice [15] [16].

The implementation of value based programs has stimulated additional interest in the use of nursing case management on a community wide basis. This includes use of it in primary and ambulatory care. This role emphasizes the use of case management for coordination of services at the community level. This is the arena where most health care services are delivered. The community level is also the location of primary care and ambulatory care services that are important to value based purchasing [15]. Nursing case managers are largely the drivers of care management and disease prevention programs for patients that are high risk and/or high cost, the focus of value based purchasing programs [14].

\section{Population}

This study described potential uses of nursing case management to address health care utilization related to value based purchasing in the metropolitan area of Syracuse, New York. Most of the case management in this area has been developed by the Syracuse hospitals. They include Crouse Hospital (19,790 discharges excluding well newborns, 2015), St. Joseph's Hospital Health Center (24,808 discharges excluding well newborns, 2015), and Upstate University Hospital (28,236 discharges excluding well newborns, 2015).

The Syracuse hospitals provide primary and secondary acute care to an immediate service area with a population of approximately 600,000 . They also provide tertiary services to the Central New York Health Service area with a population of approximately $1,400,000$ [17].

The Syracuse hospitals have employed nursing case management to address a number of utilization and outcomes issues. These include programs to reduce inpatient lengths of stay between 1983 and the present and efforts to reduce inpatient readmissions beginning in 2012. A number of these programs have been coordinated by the Hospital Executive Council, the planning organization for the hospitals [18] [19].

The implementation of value based programs in the service area of the Syracuse hospitals is being generated through the three major payers. The largest component of hospital discharges involves Medicare, through the MACRA program. They also include Medicaid through the Delivery System Reform Incentive Payment (DSRIP), a program focusing on reduction of hospital admissions and emergency department visits administered by New York State government. The largest health insurance payer in the local market, Excellus Blue Cross Blue Shield, is implementing value based purchasing as an Accountable Care and Quality Arrangement (ACQA) program.

Each of the Syracuse hospitals is planning to address value based purchasing. This study summarizes the background and potential of some of these initiatives. 


\section{Method}

The major focus of MACRA and other value based programs is reduction of the costs of expensive services such as hospital admissions and emergency department visits through judicious use of services across the health care continuum. Physicians who reduce hospital admissions and emergency department visits will be rewarded financially. Those who do not will be penalized. Historically, the Hospital Executive Council has tracked these indicators for the Syracuse hospitals.

This study was developed by the case management leaders of the hospitals. They provided ethical clearance for the study.

Data for the study were developed to address the use of nursing care management in the implementation of value based purchasing. Specific components of this approach follow.

The initial component of the study involved historical data concerning hospital admissions and emergency department visits in the health care system. These indicators are a focus for nursing case management in primary care and ambulatory care with respect to value based purchasing programs. This information was identified by year for 2010-2016, the most recent 12 month periods for which data were available.

Hospital admissions were identified as discharges per 1000 population for residents of Onondaga County, the center of the Syracuse metropolitan area. The resident data for this indicator were obtained from the New York State Planning and Research Cooperative System, SPARCS, by the Hospital Executive Council.

Hospital utilization was also identified as admissions/discharges for adult medicine, the service associated with most efforts to reduce inpatient admissions. The study data were collected for total adult medicine discharges and for adult medicine discharges at Minor severity of illness in the combined Syracuse hospitals for 2011-2016. Severity of illness was identified with the All Patients Refined Diagnosis Related Group System. Data were collected by the Hospital Executive Council.

Emergency department visits and ambulances received were employed to track changes in the use of this service. Both were collected from Hospital Executive Council data. Visits were obtained from the individual Syracuse hospitals. Ambulance transports were obtained from a software system that connects the hospitals.

The second component of the study focused on another component of hospital admissions and discharges under MACRA, inpatient readmissions within 30 days. It included numbers of annual readmissions and readmission rates for adult medical-surgical patients between 2012 and 2016. These data were generated using the Potentially Preventable Readmissions software developed by $3 \mathrm{M}^{\mathrm{mm}}$ Health Information Systems. This information reflected the impact of nursing case management programs addressing readmissions at two of the hospitals. 
The third component of the study focused on the use of case management to develop Subacute and Complex Care Programs in the Syracuse hospitals. These programs were employed to reduce hospital lengths of stay for discharges to nursing homes, however, they could also be used to address other components of health are utilization.

The Subacute and Complex Care programs were developed by case managers to address the needs of patients requiring long term acute care in the Syracuse hospitals. Through them, nursing care management extended from coordinating to creating services. The programs were based on studies of factors responsible for the longest hospital stays. They included Subacute Programs responsible for individual therapies such as intravenous medications and extended wound care, as well as Complex Care programs that involved multiple therapies. The Hospital Executive Council has coordinated the programs.

Data concerning lengths of stay for discharges to nursing homes were based on severity of illness for adult medicine and adult surgery patients in the combined Syracuse hospitals for 2008-2015. These data were developed using the All Patients Refined Diagnosis Related Group System developed by $3 \mathrm{M}^{\mathrm{sm}}$ Health Information Systems. The system is based on the principal and secondary diagnoses, as well as demographic indicators such as age, gender, and residence.

The fourth component of the study focused on examples of the potential costs and benefits of nursing case management under value based purchasing. It involved data related to adult medicine admissions/discharges at Minor severity of illness in the Syracuse hospitals. This population has high potential for avoidance of admissions under Medicare, Medicaid, and private insurance programs.

In this analysis, the potential costs and benefits of avoiding 2 percent, 5 percent, 10 percent, and 15 percent of 4100 annual adult medicine Minor severity admissions in the combined Syracuse hospitals were identified. Costs were based on case management services for experienced professionals and alternative services for home care and medications in the community. Benefits were based on assumed payments for all payers in the community.

\section{Results}

The initial component of the analysis included hospital adult medicine admissions/discharges and emergency department visits in the metropolitan area of the Syracuse hospitals. Related data are summarized in Table 1.

Reduction of hospital inpatient admissions and emergency department visits is a major objective of value based purchasing because of the costs of these services. The study focused on adult medicine admissions because of the potential impact of case management on this population.

The study demonstrated that, between 2011 and 2016, the number of total adult medicine discharges in the combined Syracuse hospitals declined by 7.0 percent, from 32,503 to 30,235 . During the same period, the number of adult medicine discharges at Minor severity of illness declined by 14.9 percent, from 
Table 1. Selected utilization indicators, Syracuse Hospitals, 2011-2016.

\begin{tabular}{|c|c|c|c|c|c|c|}
\hline & 2011 & 2012 & 2013 & 2014 & 2015 & 2016 \\
\hline $\begin{array}{l}\text { Onondaga County Resident Discharges } \\
\text { Medical/Surgical and Pediatric Neonatal }\end{array}$ & 86.4 & 87.9 & 84.2 & 86.9 & 89.9 & N/A \\
\hline Adult Medicine Discharges & 32,503 & 34,252 & 33,192 & 32,706 & 33,120 & 30,235 \\
\hline $\begin{array}{l}\text { Adult Medicine Discharges } \\
\text { - Minor Severity of Illness }\end{array}$ & 4,831 & 4,874 & 4,375 & 4,224 & 4,078 & 4,112 \\
\hline Emergency Department Visits & 184,570 & 199,344 & 201,968 & 210,794 & 215,763 & 215,207 \\
\hline Ambulance Transports Received & 57,012 & 61,583 & 62,516 & 66,081 & 67,774 & 62,707 \\
\hline
\end{tabular}

4831 to 4112 . Much of these reductions occurred because of the movement of a large number of adult medicine inpatients to medical observation status beginning in October 2013. This change had a disproportionate impact on low severity of illness admissions because they had the most potential to be served without inpatient admission in 2016. The population was stable during this period.

This information suggested that, during 2015 and 2016, adult medicine utilization at Minor severity of illness had stabilized at approximately 4100 annual discharges in the combined Syracuse hospitals. This equated to approximately 342 discharges per month. For case management purposes, this level amounted to a guideline for monitoring reduction of hospital inpatient admissions for this population under value based purchasing. The same approach suggested a guideline of approximately 30,000 annual adult medicine discharges, or 2500 per month for the combined hospitals.

The data in Table 1 also demonstrated that emergency department utilization, another focus on value based purchasing programs, increased markedly in the Syracuse hospitals between 2015 and 2016. Annual emergency department visits increased by 16.6 percent, from 184,570 to 215,207, between 2011 and 2015 before stabilizing at 215,000 between 2015 and 2016. Annual ambulance transports received increased by 18.8 percent, from 57,012 to 67,774, between 2011 and 2015 before declining by 7.5 percent to 62,707 between 2015 and 2016 .

These data demonstrated that, in contrast to adult medicine admissions/ discharges, emergency department utilization in the combined Syracuse hospitals increased for most of the period between 2011 and 2015. This indicator began to stabilize or decline only within the past two years. For case management purposes, the levels between 2015 and 2016 will be monitored to determine whether value based purchasing causes the recent reductions to be sustained.

The second component of the study focused on adult medical-surgical readmissions in the Syracuse hospitals between 2012 and 2016. Related data are summarized in Table 2. 
Table 2. Potentially preventable readmissions within 30 days, adult medical/surgical patients-all payors, Syracuse Hospitals, January 2012-September 2016.

\begin{tabular}{lccccc}
\hline & $\begin{array}{c}\text { January- } \\
\text { December } \\
2012\end{array}$ & $\begin{array}{c}\text { January- } \\
\text { December } \\
2013\end{array}$ & $\begin{array}{c}\text { January- } \\
\text { December } \\
2014\end{array}$ & $\begin{array}{c}\text { January- } \\
\text { December } \\
2015\end{array}$ & $\begin{array}{c}\text { January- } \\
\text { September } \\
2016\end{array}$ \\
\hline Number of Readmissions & 4129 & 4154 & 4020 & 4000 & 3066 \\
At Risk Population & 48,248 & 51,354 & 51,990 & 53,012 & 40,867 \\
Readmission Rate & 8.56 & 8.09 & 7.73 & 7.55 & 7.50 \\
$\begin{array}{l}\text { Data exclude obstetrics, pediatrics, psychiatry, alcohol/substance abuse treatment, rehabilitation, and } \\
\text { all patients aged 0 - 17 years. }\end{array}$
\end{tabular}

The reduction of inpatient hospital readmissions has been a challenge for hospitals in Syracuse and elsewhere because many of these patients require services that are not available outside hospitals in the community. Reduction of these readmissions will be an objective under value based purchasing.

The data in Table 2 indicated that the adult medical-surgical readmission rate for the Syracuse hospitals declined by 11.8 percent between 2012 and 2015, while the annual number of readmissions declined by 3.1 percent. Most of the reduction in the rate occurred as the total at risk population increased, rather than as a result of a decline in the original readmission population.

These data suggested that the nursing case management programs in the Syracuse hospitals were able to support declines in the readmission rate addressing additional adult medical-surgical patients in the community. This impact was produced through increased coordination with ambulatory care and long term care services. The impact was limited by the extent of alternative services available for patients who need rehospitalization in the community.

The third component of the study focused on the development of Subacute and Complex Care Programs by nursing case management to reduce inpatient lengths of stay for inpatient lengths of stay for adult medicine and adult surgery in the Syracuse hospitals. Related data are summarized in Table 3.

In the Syracuse hospitals, inpatient stays have been an indicator of the impact of nursing case management for a number of years. As in the case of adult medicine admissions/discharges, this impact has been complicated by the movement of adult medicine patients to observation status.

Between 2008 and 2016, inpatient lengths of stay in the Syracuse hospitals were impacted by the implementation of Subacute and Complex Care Programs developed by nursing case managers. These programs were created to address the needs of patients with the longest stays, those requiring long term acute care services for multiple intravenous antibiotics, extended wound care, dialysis, and other services. These services demonstrated the ability of nursing case management to address community needs by creating new services, as well as by coordinating care.

The data in Table 3 demonstrated that adult medicine inpatient stays in the combined hospitals increased by 6.0 percent, from 5.14 to 5.45 days, between 
Table 3. Inpatient mean lengths of stay, adult medicine and adult surgery, Syracuse Hospitals, 2008, 2010, 2012, 2014, 2016.

\begin{tabular}{|c|c|c|c|c|c|}
\hline & 2008 & 2010 & 2012 & 2014 & $2016^{*}$ \\
\hline \multicolumn{6}{|l|}{ Adult Medicine } \\
\hline Number of Discharges & 28,565 & 32,221 & 35,274 & 33,421 & 30,876 \\
\hline Mean Length of Stay & 4.98 & 5.18 & 5.14 & 5.45 & 5.07 \\
\hline Excess Patient Days & $8,569.50$ & $10,955.14$ & $4,938.36$ & $8,355.25$ & $2,778.84$ \\
\hline \multicolumn{6}{|l|}{ Adult Surgery } \\
\hline Number of Discharges & 19,241 & 19,170 & 20,439 & 20,562 & 20,792 \\
\hline Mean Length of Stay & 6.23 & 6.25 & 6.04 & 6.04 & 5.86 \\
\hline Excess Patient Days & $11,544.60$ & $6,901.20$ & $5,927.31$ & $1,850.58$ & $-4,158.40$ \\
\hline $\begin{array}{l}\text { Long Term Care and } \\
\text { Subacute Program Patients }\end{array}$ & 185 & 166 & 104 & 139 & 81 \\
\hline \multicolumn{6}{|c|}{${ }^{\star 2} 2016$ length of stay data annualized based January - October 2016 actual experience. } \\
\hline \multicolumn{6}{|c|}{$\begin{array}{l}\text { Adult medicine data exclude Diagnosis Related Groups concerning surgery, obstetrics, pediatrics, } \\
\text { psychiatry, alcohol/substance abuse treatment, rehabilitation, and all patients aged } 0-17 \text { years. }\end{array}$} \\
\hline
\end{tabular}

2012 and 2014, the period when the medical observation regulations were implemented, before declining to 5.07 days in 2016. This impact was supported by the decline in adult medicine discharges that occurred between 2012 and 2014.

Between 2008 and 2016, adult surgery inpatient stays declined by 5.9 percent, from 6.23 to 5.86 days, in the combined hospitals as admissions/discharges for this service continued to increase. The negative number of excess days for 2016 was produced by a hospital stay that was shorter than the severity adjusted national average.

This contrast demonstrated the impact of changes in the inpatient medicine population. The shift of some adult medicine admissions to observation status caused the inpatient length of stay for remaining inpatients to increase between 2012 and 2014. Inpatient stays for adult surgery, which were not impacted by the shift, continued to decline.

The fourth component of the study involved a summary analysis of the costs and benefits of nursing case management related to reduction of hospital admissions/discharges in the combined Syracuse hospitals. Related data are summarized in Table 4.

These cost and benefit data were developed based on summary assumptions concerning the 4,100 annual adult medicine Minor severity of illness patients for all payers in the Syracuse hospitals identified in Table 1. The numbers of these patients were based on conservative estimates of proportions of these patients, 
Table 4. Estimated costs and benefits, reducing Minor severity of illness admissions/discharges, Syracuse Hospitals.

\begin{tabular}{lcccc}
\hline & \multicolumn{4}{c}{ Percent Reduction in Minor Severity of Illness Admissions } \\
\cline { 2 - 5 } & $2 \%$ & $5 \%$ & $10 \%$ & $15 \%$ \\
\hline Number of Admissions & 82 & 206 & 411 & 617 \\
Case Management Time (Hours) & 984 & 2,472 & 4,932 & 7,404 \\
Case Management Expenses & $\$ 49,200$ & $\$ 123,600$ & $\$ 246,600$ & $\$ 370,200$ \\
Home Care/Medication Expenses & $\$ 205,000$ & $\$ 515,000$ & $\$ 1,027,500$ & $\$ 1,542,500$ \\
Total Expenses & $\$ 254,200$ & $\$ 638,600$ & $\$ 1,274,100$ & $\$ 1,912,700$ \\
Hospital Costs Avoided & $\$ 328,000$ & $\$ 824,000$ & $\$ 1,644,000$ & $\$ 2,468,000$ \\
Difference & $\$ 73,800$ & $\$ 185,400$ & $\$ 369,900$ & $\$ 555,300$ \\
\hline
\end{tabular}

for whom hospitalization could be avoided, ranging from 2 percent to 15 percent. This amounted to between 82 and 617 patients.

The cost data suggested that, at 12 hours of case management at $\$ 50$ per hour, these expenses would range from $\$ 49,200$ for 2 percent of the population to $\$ 370,200$ for 15 percent of the population. Based on costs of home care and medications estimated at $\$ 2500$ per patient, the data suggested expenses ranging from $\$ 205,000$ for 2 percent of the population to $\$ 1,542,500$ for 15 percent of the population. This amounted to a range in expenses from $\$ 254,200$ to $\$ 1,912,700$.

The benefits of avoiding these hospital admissions at $\$ 4000$ per patient ranged from $\$ 328,000$ for 2 percent of the population to $\$ 2,468,000$ for 15 percent of the population. Including the expenses for alternative services, this produced an estimated savings from $\$ 73,800$ to $\$ 555,300$.

\section{Discussion}

The implementation of the Medicare Access and Chip Reauthorization Act (MACRA) promises to bring major changes to the delivery of health care in communities throughout the United States. By providing incentives for making more judicious use of services across the continuum, it will result in fewer hospital admissions, readmissions, and emergency department visits.

Historically, Medicare has provided leadership on the implementation of programs to improve the efficiency of health care utilization, such as hospital reimbursement by discharges in the 1980s. This experience suggests that the impact of MACRA will be extended through other payers such as the DSRIP program for Medicaid in New York State and the Blue Cross Blue Shield ACQA program.

At the community level, these developments will amount to a renewal of interest in managed care. The traditional version of this mechanism included direct involvement for payers. The current version will involve more direction and activity by providers.

These developments suggest that nursing case management should be used as an important mechanism to implement value based purchasing through the coordination of health care services at the community level. Working in support 
of primary and ambulatory care, case managers can extend their roles beyond hospitals and long term care to address utilization and outcomes throughout local health care systems. These roles will be necessary for physician practices and allied health providers, as well as hospitals, home health agencies, and nursing homes to meet the clinical and financial objectives of value based purchasing.

This study provided examples of how nursing case managers in the metropolitan area of Syracuse, New York, a small community with a population of about 600,000 will be addressing the impact of MACRA and related programs. It suggested that these activities will include monitoring of important utilization indicators, as well as development of additional services. It also suggested that these activities should go beyond coordination of existing services.

The data in this study identified baseline levels in the Syracuse hospitals for case management under value based purchasing utilization indicators including hospital admissions/discharges, emergency department visits, and hospital readmissions. Each of these had a different context. Adult medicine discharges stabilized after the impact of the medical observation regulations was absorbed. Emergency department visits stabilized after a lengthy period of increases. Adult medicine and adult surgery readmissions have declined at a gradual rate. Using these types of data for major value based indicators, nursing case managers should be able to implement approaches to produce additional efficiencies.

The experiences of the Syracuse hospitals suggest that one approach to these efficiencies can be the development of new levels of care similar to the Subacute and Complex Care Programs. These initiatives grew out of the experiences of nursing case managers related to length of stay reduction. They involved the development of new services for long term acute care. They could also be applied to ambulatory care patients in order to avoid hospital admissions and emergency department visits. They could also be employed to reduce inpatient readmissions with nursing home alternatives.

The study also indicated that the use of case management to reduce utilization of expensive services, such as hospital admissions, can generate financial benefits for health care payers. Estimating the amounts of these benefits requires identification of the costs of case management and the alternative services it employs.

This information demonstrates that the advent of MACRA and other value based purchasing programs will provide important opportunities for health planning and development at the community level. They suggest that nursing case management can be a major tool to address these needs.

\section{References}

[1] Dentzler, S. (2011) Urgent Measures for an Old Problem. Health Affairs, 30, 1626. https://doi.org/10.1377/hlthaff.2011.0961

[2] Toone, K. and Muhlstein, D. (2016) MACRA: Quality Incentives, Provider Considerations, and the Path Forward. Leavitt Partners, New York.

[3] Barkholz, D. (2016) Under Construction: Risk Based Reimbursement. Modern Healthcare, 46, 14-18. 
[4] Muchmore, S. (2016) Few Docs Ready for Risk. Modern Healthcare, 46, 20-22.

[5] Advisory Board (2016) Our First Thoughts on the MACRA Final Rule. Advisory Board, Washington DC.

[6] Van Dyke, M. (2016) Make Way for MACRA. Hospitals and Health Networks, 90, 27-31.

[7] Rau, J. (2012) Medicare to Penalize 2,211 Hospitals for Excess Readmissions. Kaiser Health News.

[8] Aguilar, A., Dickson, V. and Whitman, E. (2016) Trump's HHS Nominees Tee up Obamacare Repeal Effort. Modern Healthcare, 46, 8-9.

[9] Whitman, E. (2016) Will Value Based Payment Initiatives Continue Under Trump? Modern Healthcare, 46, 18.

[10] Dickson, V. (2017) Republicans Target Medicaid, Medicare for Big Changes. Modern Healthcare, 47, 18.

[11] Rose, S., Zaslavsky, A.M. and McWilliams, J.M. (2016) Variation in Accountable Care Organization Spending and Sensitivity to Risk Adjusting: Implications for Benchmarking. Health Affairs, 35, 440-448. https://doi.org/10.1377/hlthaff.2015.1026

[12] Tahan, H.A. (1999) Clarifying Case Management: What Is in a Label? Nursing Case Management, 4, 268-278.

[13] Ahmed, O.I. (2016) Disease Management, Case Management, and Care Coordination. A Framework and Brief Manual for Care Programs and Staff. Professional Case Management, 25, 137-146.

[14] Mullahy, C. (2017) Case Manager's Handbook. 6th Edition, Jones and Bartlett Learning, Burlington, 548.

[15] Joo, J.Y. and Huber, D.L. (2014) Evidence Based Nursing Case Management in Community Health. Professional Case Management, 19, 265-273.

https://doi.org/10.1097/NCM.0000000000000058

[16] American Nurses Association (2013) The Supreme Court Decision Matters for Registered Nurses, Their Families, and Their Patients. www.nursingworld.org

[17] Lagoe, R., Pasinski, T., Kronenberg, P., Quinn, T. and Schaengold, P. (2006) Linking Health Services at the Community Level. Canada Healthcare Quarterly, 9, 6065. https://doi.org/10.12927/hcq..18229

[18] Lagoe, R.J., Westert, G.P., Kendrick, K., Morreale, G. and Mnich, S. (2005) Managing Hospital Length of Stay Reduction: A Multihospital Approach. Health Care Management Review, 30, 89-92. https://doi.org/10.1097/00004010-200504000-00002

[19] Lagoe, R.J., Nanno, D.S. and Luziani, M.E. (2012) Quantitative Tools for Addressing Hospital Readmissions. BMC Research Notes, 5, 620.

https://doi.org/10.1186/1756-0500-5-620 
Submit or recommend next manuscript to SCIRP and we will provide best service for you:

Accepting pre-submission inquiries through Email, Facebook, LinkedIn, Twitter, etc. A wide selection of journals (inclusive of 9 subjects, more than 200 journals)

Providing 24-hour high-quality service

User-friendly online submission system

Fair and swift peer-review system

Efficient typesetting and proofreading procedure

Display of the result of downloads and visits, as well as the number of cited articles Maximum dissemination of your research work

Submit your manuscript at: http://papersubmission.scirp.org/

Or contact ojn@scirp.org 